\title{
Inmovilización de la proteína fotoactiva bacteriorodopsina sobre óxido de zinc Aplicación en Celdas Solares Bio-Sensibilizadas
}

Immobilization of the photoactive protein bacteriorhodopsin on zinc oxide Application in Bio-Sensitized Solar Cells

\section{Alejandro Martínez-Brenes ${ }^{1}$, Claudia Chaves-Villarreal ${ }^{2}$}

Martínez-Brenes, A; Chaves-Villareal, C. Inmovilización de la proteína fotoactiva bacteriorodopsina sobre óxido de zinc. Aplicación en Celdas Solares Bio-Sensibilizadas. Tecnolog ía en Marcha. Edición especial. Movilidad Estudiantil 6, 2019.

Pág 104-118

doi) https://doi.org/10.18845/tm.v32i8.4568 


\section{Palabras clave}

Bacteriorodopsina; celdas solares sensibilizadas; óxido de zinc; sedimentación electroforética; fotorespuesta; conversión de energía; celdas biofotovoltaicas; biofuncionalización

\section{Resumen}

En este proyecto se construyeron fotoánodos para celdas solares sensibilizadas utilizando la proteína fotoactiva bacteriorodopsina (BR). El objetivo fue utilizar la proteína como sustituyente a los colorantes comunes a base de Ru, que son costosos y tóxicos. Los sustratos se prepararon recubriendo vidrio conductor con nanopartículas de óxido de zinc (ZnO-NPs). La proteína se inmovilizó en estos sustratos para completar un fotoánodo capaz de capturar la energía solar y transformarla en energía eléctrica. Las técnicas de dropcasting (DC), funcionalización química con feniltrietoxisilano (PTES) y la sedimentación electroforética (SE) fueron optimizadas para inmovilizar la proteína. Mediante espectroscopia de absorción ultravioleta-visible (UV-Vis) se demostró que la proteína conservaba su función fotoactiva después de la inmovilización. La resistencia y tasa de transferencia de carga del fotoánodo en el electrolito fue comparada por medio de impedancia electroquímica. Para los tres métodos se encontraron valores relativamente altos $\left(10^{5} \Omega\right.$ ) en comparación con datos reportados para tintes de rutenio. El desempeño de los fotoánodos preparados por DC y SE en celdas solares sensibilizadas se determinó por cronopotenciometría bajo iluminación. Se encontró que la capa molecular de PTES permite inmovilizar la proteína en periodos más cortos de tiempo pero introduce una resistencia eléctrica adicional en el sistema, por lo que no es apropiada para el sistema fotoelectroquímico estudiado. Los fotoánodos preparados por SE permite obtener el fotovoltaje más alto (16 mV) y la tasa de transferencia electrónica más veloz, mientras que usando la técnica DC se midieron fotovoltajes de tan solo $1 \mathrm{mV}$. Estas respuestas sugieren que la orientación de la proteína en el $\mathrm{ZnO}$ es determinante en la fotorespuesta de la celda, ya que bajo el campo eléctrico aplicado durante SE la proteína se orienta según su dipolo eléctrico, mientras en el DC, la orientación es aleatoria. En base a los resultados obtenidos, se recomienda controlar mejor el espesor de la capa de la proteína, utilizar un electrolito más afín a la naturaleza de esta biomolécula y disminuir la rugosidad de la capa de ZnO para producir fotoánodos que transformen la energía solar de forma más eficiente.

\section{Keywords}

Bacteriorhodopsin; Sensitized SolarCells; Zinc oxide; electrophoretic sedimentation; photoresponse; energy conversion; bio-photovoltaic cells; biofunctionalization.

\section{Abstract}

This project deals with the development of photoanodes for sensitized solar cells using the photoactive protein bacteriorhodopsin (BR) as the sensitizer. The purpose was to integrate the protein in substitution of the commonly used Ru-base dyes, which are expensive and toxic. Substrates were prepared by spreading a thin film of zinc oxide ( $\mathrm{ZnO}$ ) nanoparticles (NPs) over conductive transparent glass. The photoanode capable of convert the energy of light directly into electricity was completed by immobilizing the protein in the substrate. The techiniques dropcasting (DC), pheniltriethoxysilane chemical functionalization (PTES) and electrophoretic sedimentation (SE) were optimized to immobilized the protein. Through ultraviolet spectroscopy absorbance (UV-VIS) analysis was assessed the remaining photoactive functionality of the protein after immobilization. The charge transfer resistance of the photoanodes in the electrolyte 
were compared by electrochemical impedance curves, for all the methods it was found relatively high values (105 $\Omega$ ) in comparison with the Ru-base dyes. The performance of the photoanodes prepared as sensitized solar cells with DC and SE techniques, were determined by chronopotentiometry and electrochemical impedance under illumination. It was found that the molecular layer of PTES allows to reduce the time to impregnated the BR but induced an additional electrical resistance and thus is not appropriate for the studied photoelectrochemical system. The photoanodes prepared by SE archived the highest photovoltage (16 $\mathrm{mV})$, while with the DC, photovoltage of merely $1 \mathrm{mV}$ were obtained. These results suggest that the orientation of the protein in the $\mathrm{ZnO}$ was determinant in the cell photoresponse because under the electric field applied with the SE, the protein is forced to be oriented according to its electric dipole while with DC technique, the orientation is random and uncontrollable. On the basis of the results obtained, it is recommended to have a better control of the protein film thickness, use an electrolyte more compatible to the protein naturalness and reduce the $\mathrm{ZnO}$ thin film roughness in order to produce more efficient photoanodes.

\section{Introducción}

Las celdas solares se han convertido en uno de los dispositivos más investigados mundialmente por su potencial para obtener energía de una forma más sostenible, en comparación con el uso de combustibles fósiles. A pesar de que las celdas solares de silicio (Si) han alcanzado eficiencias de conversión eléctrica dentro de un rango del 15 al 32\%, los elevados costos de fabricación y el uso de químicos tóxicos para alcanzar una alta pureza del silicio durante su manufactura ha motivado la búsqueda de celdas solares de bajo costo y amigables con el ambiente [1] [2].

Una nueva variante de celda solar que está siendo investigada actualmente es la celda solar sensibilizada con colorante (DSSC, por sus siglas en inglés dye-sensitized solar cell). Estas han ganado popularidad en la última década por ser dispositivos más baratos y que requieren menor energía durante su manufactura que las celdas a base de Si. Estas se reportaron por primera vez en 1991 cuando Brian O' Regan y Michael Gratzel publicaron en la revista Nature [3] los resultados obtenidos de la construcción de una novedosa celda solar por un fotoánodo, un electrolito y un contraelectrodo (figura 1). El fotoánodo, en la que se va a enfocar este estudio, está basado en una molécula fotoactiva (colorante) inmovilizada en la superficie de un semiconductor poroso nanoestructurado de banda ancha esparcido sobre un vidrio conductor. El colorante absorbe luz y sus electrones son excitados desde su orbital molecular más ocupado (HOMO por sus siglas en inglés, Highest Occupied Molecular Orbital) hasta el orbital molecular menos ocupado (LUMO, por sus siglas en inglés, Lowest Unoccupied Molecular Orbital). De ahí, el electrón es inyectado en la banda de conducción del semiconductor y finalmente transferido a la capa transparente conductora que recubre el vidrio. El colorante se regenera por la oxidación del electrolito, usualmente un par $1 / \mathrm{I}_{3}^{-}$. En el contraelectrodo ocurre la reducción del electrolito, completando el ciclo de trasferencia de carga. A diferencia de las celdas de Si, en las DSSC la eficiencia de la separación y transferencia de cargas depende radicalmente de su competencia cinética con las reacciones de recombinación que ocurren simultáneamente en el fotoánodo. La mayor eficiencia de conversión que se ha obtenido con las DSSC es de 11\% utilizando colorantes organometálicos sintéticos a base Rutenio, los cuales lamentablemente pueden causar problemas durante su producción masiva por sus efectos tóxicos al ambiente. 


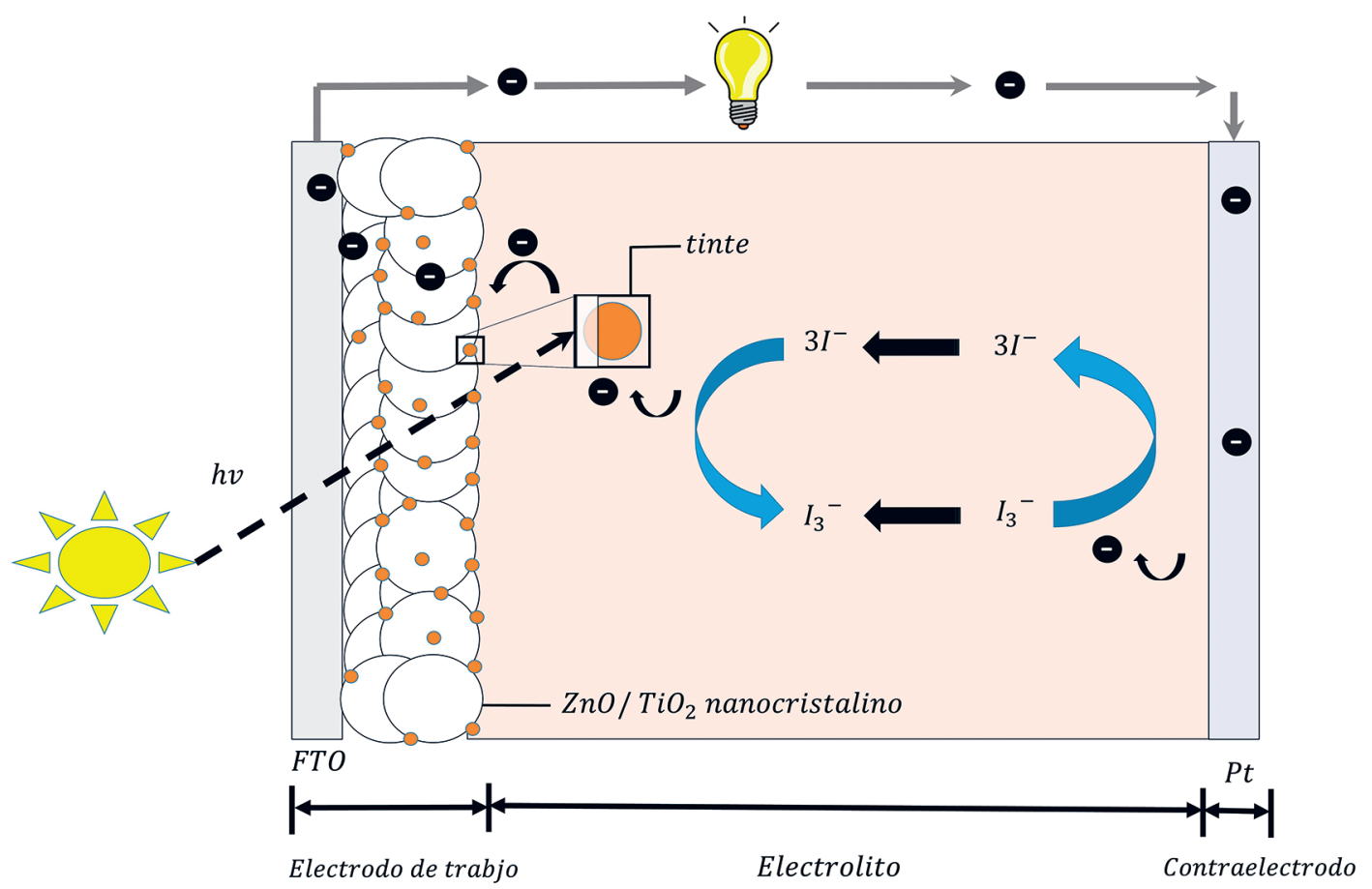

Figura 1. Esquema de funcionamiento de una celda solar sensibilizada (DSSC).

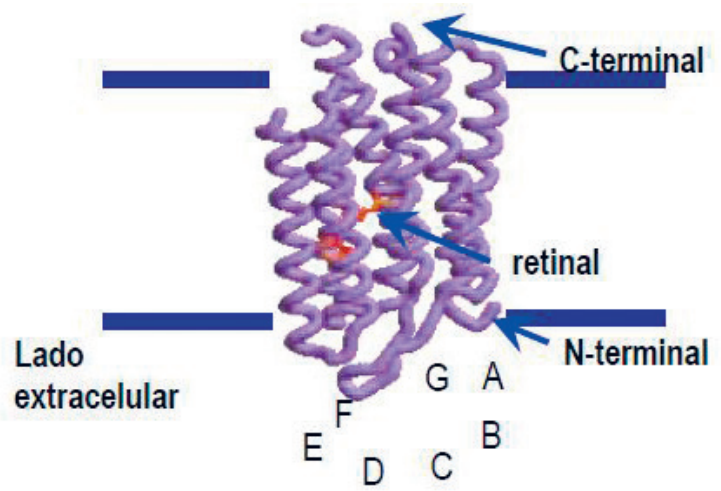

Figura 2. Estructura terciaria de la BR, las letras indicadas en la parte inferior dan nombre a las siete hélices $\alpha$. Tomado de (Vázquez, 2009).

Gran variedad de biomateriales se investiga actualmente como materiales foto-activos para hacer celdas solares bio-sensibilizadas (BSSC por sus siglas en inglés bio-sensitized solar cells) como alternativas sostenibles al uso de tintes sintéticos. Uno de los ejemplos más interesantes es la bacteriorodopsina (BR), una proteína que se encuentra en una membrana púrpura (MP) de la bacteria Halobacterium salinarum. La MP es una membrana celular que está formada por una doble capa de fosfolípidos en la cual está inmersa la BR. Esta bacteria sintetiza la MP cuando no puede llevar a cabo su proceso aerobio para obtener energía. La BR, representada en la figura 2, es una proteína de 248 aminoácidos cuya estructura consiste en 7 hélices conectadas entre sí por bucles citoplasmáticos y extracelulares con el extremo N-terminal en el lado extracelular 
y el extremo C-terminal en el lado citoplasmático. Hacia el centro de la BR se encuentra la molécula retinal unida covalentemente, que es el cromóforo responsable de la absorción de la luz y de iniciar los cambios necesarios para que la BR bombee protones. La proteína actúa como un foto-receptor que induce cambios en el $\mathrm{pH}$ del medio celular. El bombeo protones se da por la conformación de la molécula de retinal de todo-trans (adaptada a la luz) a 13-cis, 15 syn (adaptada a la oscuridad).La BR bombea protones desde el citoplasma al espacio extracelular generando un gradiente electroquímico que es aprovechado por la bacteria para generar ATP [4].La BR es una proteína biocompatible, biodegradable, no tóxica, amigable con el ambiente, que se puede producir a bajo costo, en cantidades prácticamente ilimitadas y cuyo cultivo bacteriano crece bajo condiciones industriales sin ningún requerimiento especial. Además, la BR se extrae y se purifica de la bacteria fácilmente por lo que su aplicación en sistemas optoelectrónicas es prometedor [5] [6].

El objetivo de este estudio fue fabricar el fotoánodo de una celda solar bio-sensibilizada (BRSSC por sus sigles en inglés bacteriorhodopsin-sensitized solar cell) utilizando la proteína bacteriorodopsina como bio-material foto-activo. Se estudiaron tres técnicas distintas para la inmovilización de la BR sobre la superficie del ZnO: dropcasting (DC), sedimentación electroforética (SE) y funionalización química (PTES). La funcionalidad de la BR inmovilizada sobre el ZnO se verifica mediante UV-Vis. Posteriormente, se evalúa la eficiencia de trasferencia de carga del electrolito al fotoánodo mediante impedancia electroquímica. Finalmente, eEl desempeño del fotoánodo integrado en un sistema de celda solar sensibilizada se evalúa en oscuridad y en presencia de luz visible utilizando la técnica de cronopotenciometría.

\section{Materiales y métodos}

\section{Preparación del Sustrato Vidrio Conductor/ZnO}

Se utilizó vidrio conductor, el cual está compuesto por vidrio recubierto con óxido de estaño dopado de fluor (FTO por sus siglas en inglés, fluorine-doped tin oxide) adquirido de SigmaAldrich $(\sim 7 \Omega / s q)$. Sobre la parte conductiva del FTO se depositó una capa delgada de ZnO-NPs. Las mismas se prepararon mezclando $0.5 \mathrm{mg} / \mu \mathrm{L}$ de polvo comercial (NanoTek® 40-100nm) en poli-etilenglicol (400 MW) [7] y se depositaron mediante la técnica de slip-casting [8]. Posteriormente, se les realizó un recocido en horno de calentamiento (OTF-1200x, MTI Corp) a $450^{\circ} \mathrm{C}$ durante 30 minutos.

\section{Preparación de BR y técnicas de inmovilización}

La proteína en su MP pura fue brindada por el instituto de investigación de CSIR-IMTECH en India. Esta se utilizó disuelta en solución tampón de fosfato $1 \mathrm{mM} \mathrm{pH} 7.2$ a una concentración de $2.24 \mathrm{mg} / \mathrm{ml}$. El procedimiento para llevar a cabo cada una de las técnicas de inmovilización de la proteína en el sustrato ZnO/FTO se detalla a continuación.

En la técnica de DC se depositaron $40 \mu \mathrm{L}$ de la suspensión de MP sobre el sustrato ZnO/FTO recién salido del horno a temperatura ambiente y se deja incubando durante el periodo de tiempo seleccionado.

En la técnica de PTES, el sustrato ZnO/FTO se incubó en el feniltrietoxisilano (PTES 100\%, SigmaAldrich) en baño maría a $50{ }^{\circ} \mathrm{C}$ por 1 hora. Luego se depositaron $40 \mu \mathrm{L}$ de la suspensión de BR sobre el ZnO/FTO y se deja incubando por 12 horas. Se investigó el efecto del pretratamiento del ZnO con UV/ozono (Hi Q Engineering UltraViolet Ozone Cleaner).

En la inmovilización mediante SE, se inyectaron $6 \mu \mathrm{L}$ de BR en medio del sustrato ZnO/FTO y un contraelectrodo de FTO separados por un espaciador dieléctrico de silicona (PDMS). Se aplicó 
un campo eléctrico a través de los mismos y después de un tiempo el ánodo de FTO/ZnO con la proteína impregnada fue removido. Se utilizó un analizador parametrico semicoductor (HP 4155A) para crear el campo eléctrico.

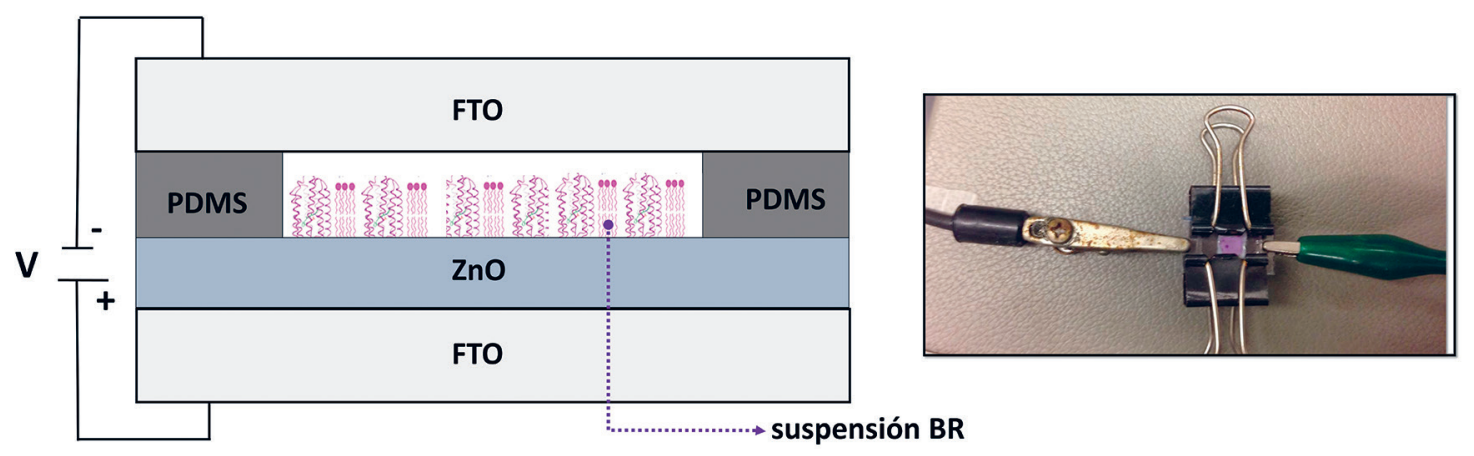

Figura 3. Montaje experimental para inmovilización de BR sobre ZnO mediante la técnica SE.

Concluida la inmovilización, los sustratos se lavaron con solución tampón de fosfato y agua desionizada para remover la proteína débilmente adherida de la superficie del ZnO.

\section{Caracterización morfológica del fotoánodo}

Mediante Microscopía de Fuerza Atómica (AFM por sus siglas en inglés atomic force microscopy) se determinó la topografía y rugosidad de la capa de ZnO. Se utilizó un Veeco MultiMode de Nanoscope en modo intermitente y con una punta de Si dopado con Antimonio (0.01-0.025 Ohm-cm). Mediante Microscopía Electrónica de Barrida (MEB) se caracterizó la interfaz ZnOBR. Se utilizó un NanoSEM450 de FEl con una fuente de electrones de efecto campo Schottky, con voltajes entre 5 y $20 \mathrm{kV}$, y presión menor a $6 \times 10^{-2} \mathrm{~Pa}$.

\section{Caracterización de las BRSSC por métodos electroquímicos}

Los fotoánodos preparados BR/ZnO/FTO se utilizaron como electrodos de trabajo en una celda solar electroquímica BRSSC. El contraelectrodo utilizado fue una malla de Pt y como electrolito el par redox I// $\mathrm{I}_{3}^{-}\left(0.1 \mathrm{M} \mathrm{Lil,} 0.03 \mathrm{M} \mathrm{I}_{2}\right)$ en $0.5 \mathrm{M} \mathrm{KCl}$ en solución acuosa. Las mediciones electroquímicas se condujeron bajo una intensidad de irradiación de $100 \mathrm{~mW} / \mathrm{cm}^{2}$ en un área fotoactiva de $0.4 \mathrm{~cm}^{2}$ utilizando un bombillo USHIO de Xe 75W conectado a una lámpara LPS220B $(\mathrm{OBB} \otimes)$. Se filtró la radiación UV en las mediciones para anular la fotorespuesta del ZnO, y así solamente medir la respuesta de la BR a la iluminación. Para determinar el desempeño de las BRSSC se aplicaron las técnicas de cronopotenciometría en circuito abierto e impedancia electroquímica con el potensiostato $\mathrm{CHI} 760 \mathrm{C}$. El potencial de circuito abierto de la celda se monitoreó tras pasar de un estado iluminado a un estado de oscuridad y viceversa. La impedancia electroquímica se midió bajo iluminación, en un rango de frecuencia de $0.1 \mathrm{~Hz}$ a $10^{5} \mathrm{~Hz}$, con el potencial de circuito abierto aplicado y una amplitud de $10 \mathrm{mV}$. 


\section{Resultados}

Morfología del sustrato

Por medio de AFM se obtuvo la topografía tridimensional de la superficie del ZnO. Se determinó que la rugosidad de la capa de $\mathrm{ZnO}$ es de $\mathrm{Rq}=138 \mathrm{~nm}$ (figura 4).

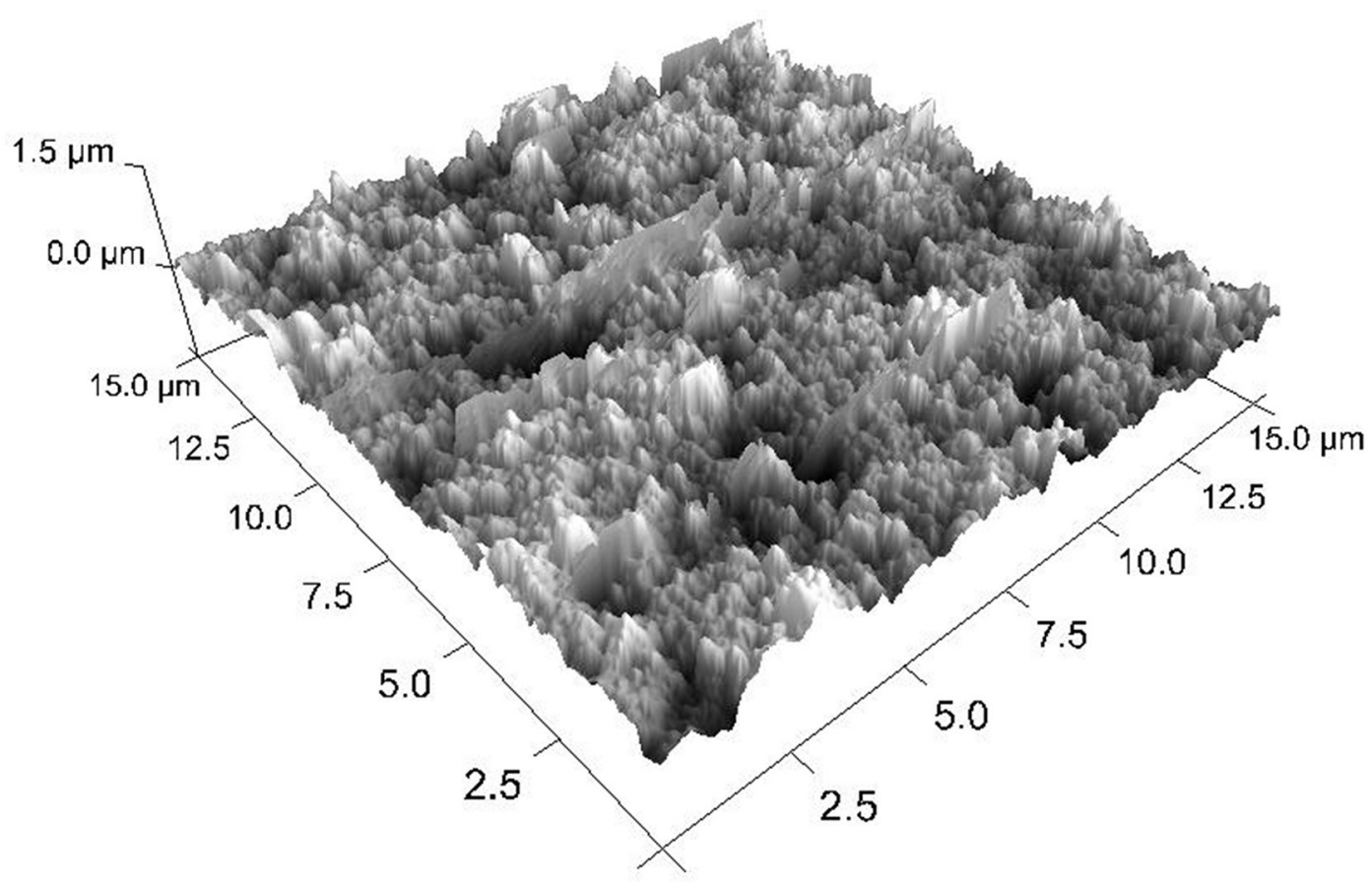

Figura 4. Micrografía de AFM del sustrato, capa de NPs de ZnO depositada sobre vidrio conductor

\section{Inmovilización de la proteína}

Inmovilización por DC:

Para la immobilización de DC se optimizaron dos variables: el tiempo de incubaciòn y la humedad del ambiente. Los resultados se ilustran en el cuadro 1. En 10 horas y a 30\% de humedad no se observó inmobilización significativa de BR. Al incrementar el tiempo de incubación a la misma humedad se incrementa la inmobilización, pero la contracción de la BR al secar produjo que la capa de ZnO se desprendiera del FTO, por efecto de la deshidratación y la rápida tasa de secado. Al aumentar la humedad e incubar por un tiempo de 16 horas, la BR se impregnó de manera efectiva sobre el sustrato sin generar falla mecánica de la capa. Los resultados indican que la tasa de deshidratación y el tiempo de secado son parámetros determinantes para lograr una impregnación efectiva de la proteína sobre el ZnO. 
Cuadro 1. Muestras preparadas mediante el método de $D C$.

\begin{tabular}{|l|c|c|c|}
\hline $\begin{array}{l}\text { Tiempo de incubación } \\
\text { (h) }\end{array}$ & 10 & 24 & 16 \\
\hline Humedad (\%) & 30 & 30 & 80 \\
\hline & 4 & \\
\hline
\end{tabular}

Para una óptima impregnación por DC, deben existir fuerzas intermoleculares lo suficientemente fuerte entre la BR y el sustrato. Por su naturaleza iónica, el ZnO se enlaza a otros materiales por fuerzas electrostáticas. La proteína tiene un dipolo eléctrico y su carga depende de su orientación sobre el ZnO. Sin embargo, el mapa electrostático de la BR podría variar con respecto a un modelo ideal de aminoácidos cargados porque las cargas internas residuales también contribuyen al potencial electrostático [9]. Por lo tanto, mientras el punto isoeléctrico del $\mathrm{ZnO}$ es de aproximadamente 9.5 (o menos en la superficie por los grupos hidroxilos), el mapa del potencial electrostático de la BR es cambiante con las cargas residuales positivas y negativas que se encuentren en la superficie y el $\mathrm{pH}$ de la misma; con lo que se dificulta producir un enlace electrostático fuerte entre ambos.

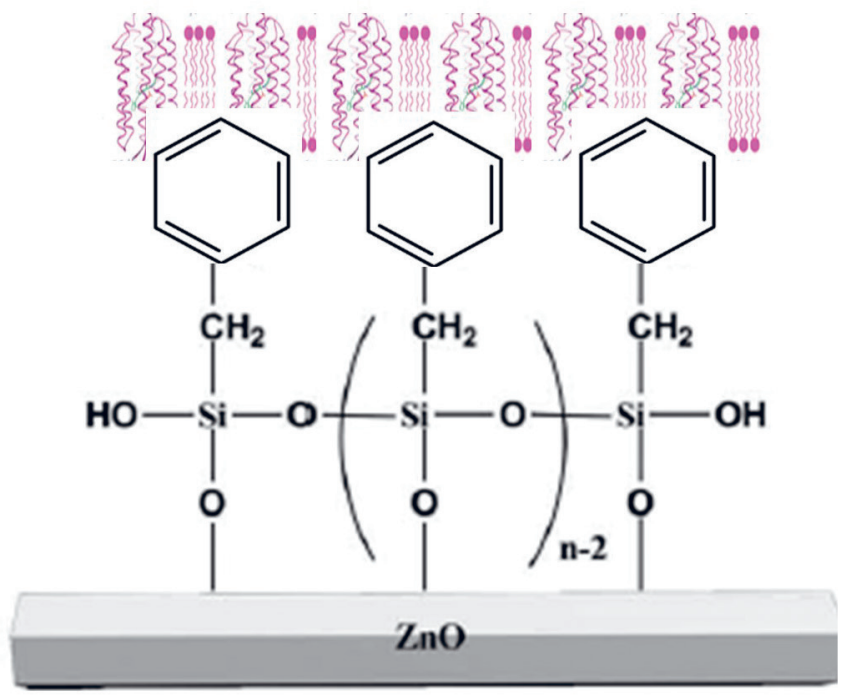

Figura 5. Inmovilización de BR sobre ZnO funcionalizado con molécula PTES.

Inmovilización por funcionalización química del ZnO:

Debido a la interacción electrostática limitada entre la BR y el ZnO observada en DC, se procedió a utilizar las fuerzas hidrofóbicas para atraer la MP al ZnO. Se usó el ligando PTES para tornar la superficie del ZnO en hidrofóbico (ver figura 5). Los resultados de la inmobilización se observan en el cuadro 2. 
Cuadro 2. Muestras preparadas mediante el método de inmovilización química

\begin{tabular}{|l|c|c|}
\hline Pretratamiento del ZnO & Ninguno & $\begin{array}{c}\text { Limpieza con UV/ozono + } \\
\text { Hidratación }\end{array}$ \\
\hline Ángulo de contacto $\left(^{\circ}\right)$ & 31 & 73 \\
\hline Resultado & & \\
& & \\
\hline
\end{tabular}

Sin tratamiento del ZnO previo a la funcionalización con PTES, el ángulo de contacto del PTES/ $\mathrm{ZnO} / \mathrm{FTO}$ se mantiene entre 40 y $31^{\circ}$. Al llevar a cabo un pretratamiento del $\mathrm{ZnO}$ por medio de UV/ozono, seguido de hidratación el ángulo de contacto incrementa a $73^{\circ}$. El pretatamiento del ZnO permitió formar una capa más uniforme del ligando, y un recubrimiento proteico más homogéneo. Durante la silanización, la hidroxilación de la molécula PTES ocurre en presencia de moléculas de agua, por lo que la hidratación de la superficie es determinante en el proceso de funcionalización [10].

\section{Inmovilización por SE}

La utilización de fuerzas hidrofóbicas para fijar la BR al ZnO no es selectivo en cuanto a la orientación de la proteína. En la BR, el bombeo de protones ocurre desde el lado citoplasmático al extracelular de la proteína, lo que intuitivamente indica una transferencia de cargas negativas en dirección inversa. Por ello lo ideal sería enlazar el lado citoplasmático de la proteína con la superficie del $\mathrm{ZnO}$ ya que éste último es un excelente aceptor de electrones. Para promover una orientación selectiva durante la fijación de la proteína se decidió aplicar un potencial eléctrico positivo para atraer el lado citoplasmático de la proteína a la superficie del ZnO. La evolución del proceso, desde tener la proteína suspendida hasta totalmente fijada por atracción eléctrica se observa en la figura 6.
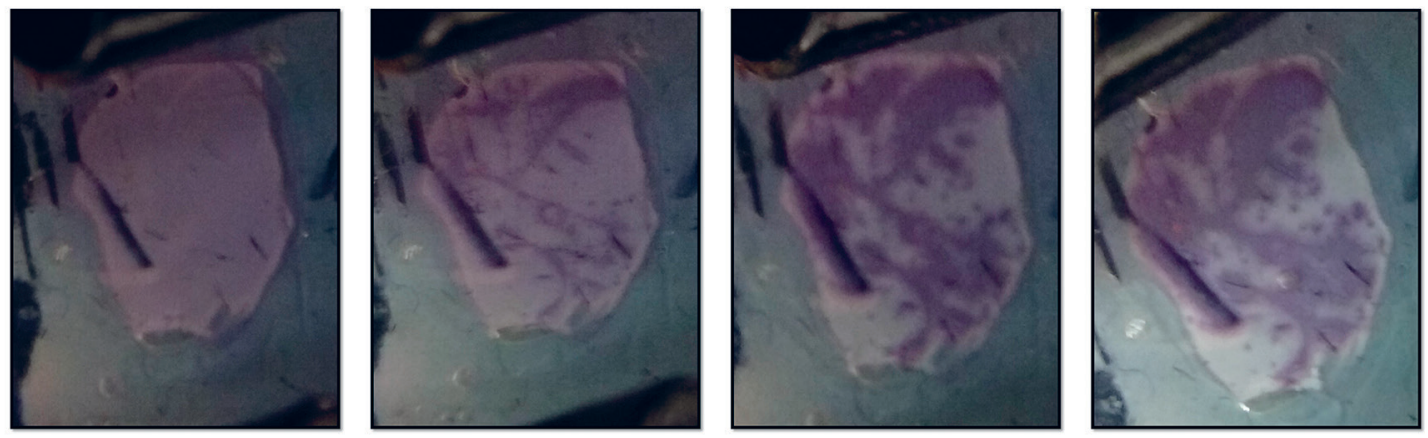

Figura 6. Proceso de impregnación por SE, de izquierda a derecha tomada cada 5 minutos con un voltaje de 50 V/cm.

Para este método se observó que la calidad de la deposición dependía del campo eléctrico aplicado (ver cuadro 3). Cuando el campo eléctrico aplicado fue de $30 \mathrm{~V} / \mathrm{cm}$, pocas moléculas de BR se lograron impregnar sobre la superficie de ZnO (mancha oscura en muestra 1), mientras que si se incrementa hasta $50 \mathrm{~V} / \mathrm{cm}$ la deposición es mucho más eficiente. Si el campo eléctrico sobrepasa cierto valor entre 55 y $60 \mathrm{~V} / \mathrm{cm}$, se comienzan a observar algunos burbujeos producto de la disociación electrolítica del agua presente en la solución tampón que resulta en un daño 
hacía la BR y la capa de ZnO. Se observa que la deposición no es uniforme, probablemente debido a variación en el espesor del ZnO que generan diferencias lo suficientemente significativas en la fuerza del campo eléctrico a lo largo de la superficie del sustrato.

Cuadro 3. Muestras preparadas mediante el método de sedimentaciòn electroforética

\begin{tabular}{|c|c|c|c|}
\hline $\begin{array}{c}\text { Campo Eléctrico [V/cm] } \\
\text { [min] }\end{array}$ & 30 & 50 & 60 \\
\hline & 10 & 20 & 10 \\
\hline Resultado & &
\end{tabular}

\section{Morfología y foto-actividad de la proteína inmobilizada en ZnO/FTO}

La presencia y funcionalidad de la proteína en el sustrato se determinó mediante un análisis UV-Vis y se presenta en la figura 7. Para la suspensión de BR se observan los picos de absorbancia característicos en el rango de 500 a $600 \mathrm{~nm}$, correspondiente a la absorbancia de la molécula retinal que está encapsulada dentro de la proteína y el pico de 250 a 300 nm correspondiente con la absorbancia de los triptófanos y las tirosinas de la proteína. Tras su inmobilización en el sustrato, estos picos todavía se pueden observar, indicando la efectiva presencia de BR en la superficie y la estabilidad de la foto-respuesta de la molécula retinal. Este pico no se observa en el blanco de $\mathrm{ZnO} / \mathrm{FTO}$.

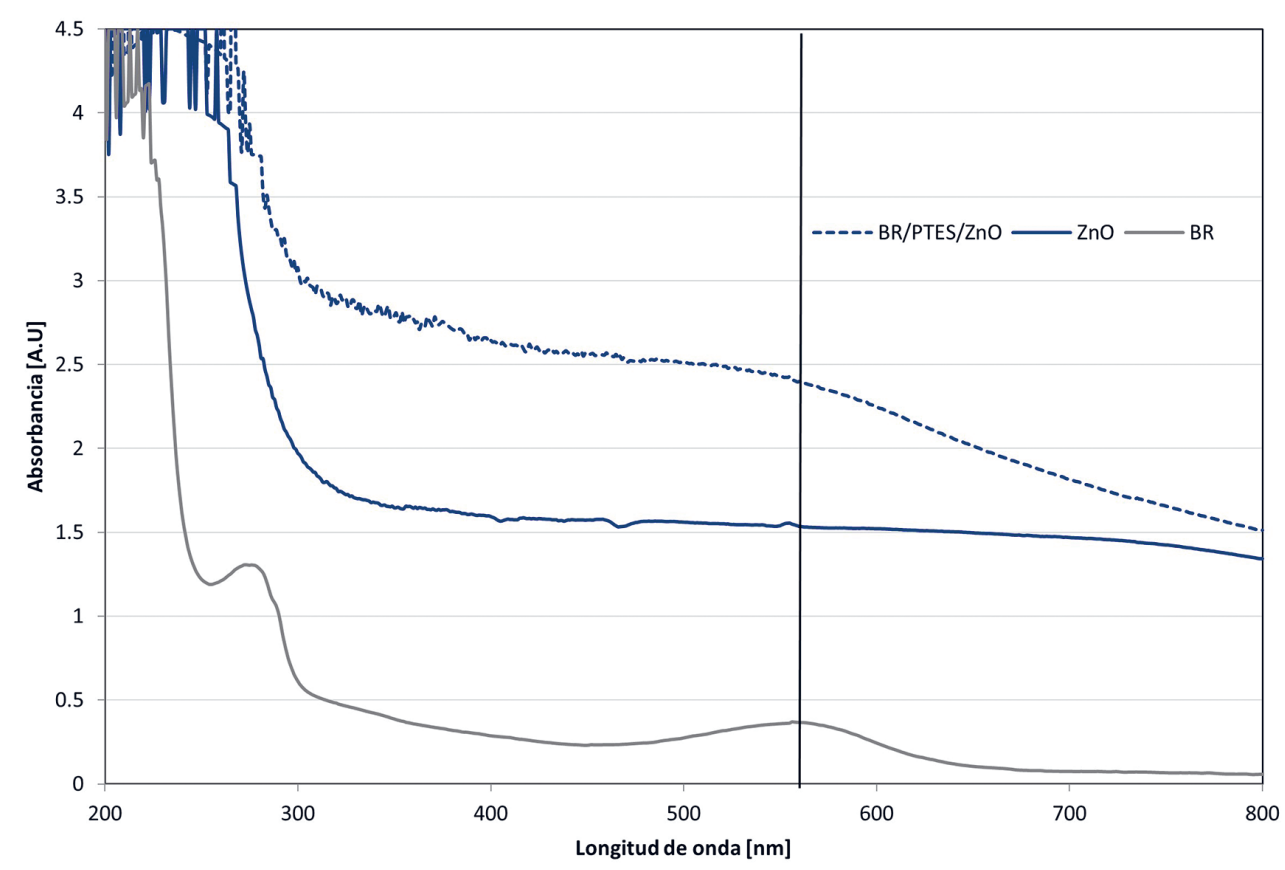

Figura 7. Curva de espectrometría UV-VIS para la BR en suspensión, el sustrato de $\mathrm{ZnO} / \mathrm{FTO}$ y la estructura híbrida $\mathrm{BR} / \mathrm{ZnO} / \mathrm{FTO}$ 
La morfología de la capa de proteína sobre el ZnO/FTO se puede observar en la micrografía electrónica de la figura 8. La BR forma un recubrimiento lamelar de multicapas con espesor de 1 a $3 \mu \mathrm{m}$ sobre la superficie de $\mathrm{ZnO}$. El recubrimiento de BR es denso y está uniformemente distribuido sobre el sustrato. Los trozos de MP no penetran la capa mesoporosa del ZnO, sino que se asientan encima.
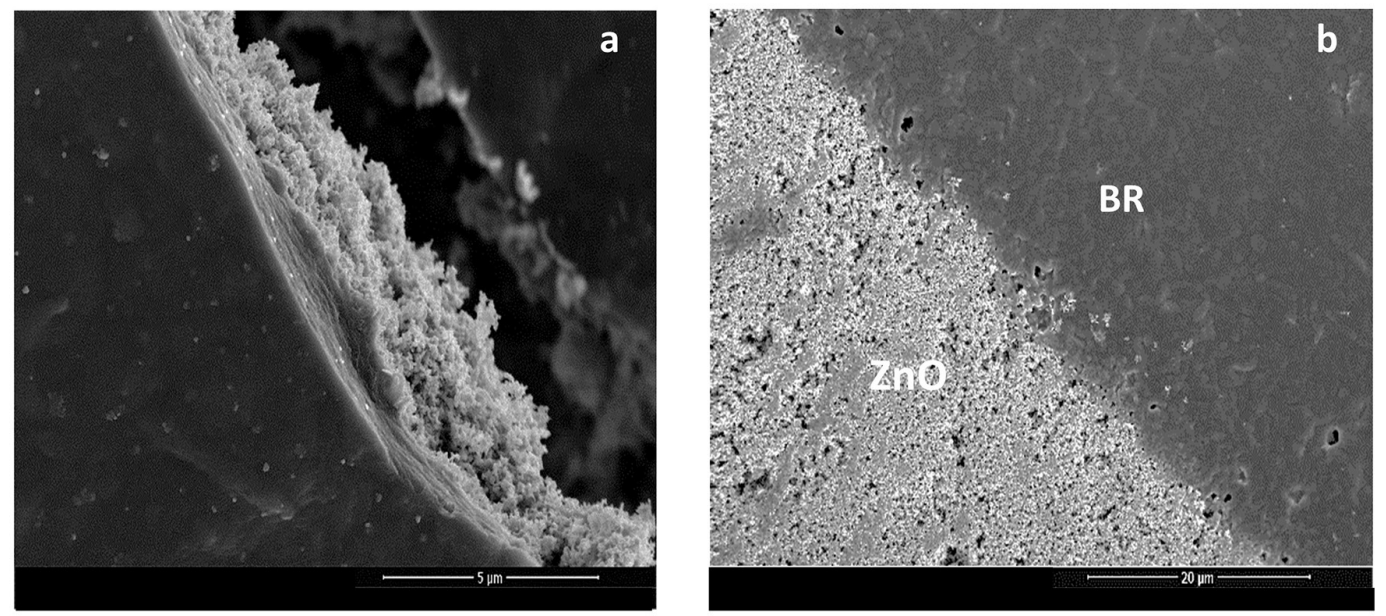

Figura 8. Micrografías MEB de bacteriorodopsina oscuro en $\mathrm{ZnO}$ a) sección transversal y b) vista superior.

Impedancia electroquímica del fotoánodo de BR/ZnO/FT0

La eficiencia de una celda solar sensibilizada depende de la facilidad de transferencia de electrones en la interfaz del fotoánodo y el electrolito. Con el fin de cuantificar esta característica se aplica la técnica de impedancia de las celdas electroquímicas construidas con los fotoánodos y se muestran en la figura $9(a-b)$.

(a)

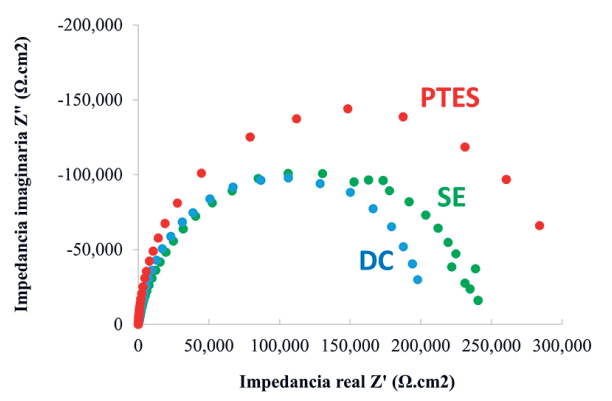

(b)

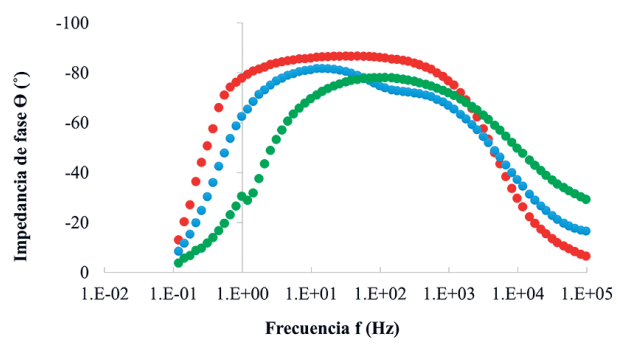

(c)

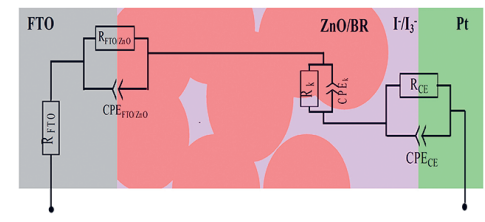

Figura 9. (a) Diagrama de Nyquist y (b) diagrama de fase de Bode de impedancia para las celdas solares biosensibilizadas con BR usando las técnicas de dropcasting (azul), funcionalización química (rojo) y sedimentción electroforética (verde). (c) Circuito equivalente de la celda, donde el color gris representa el FTO, el rojo representa el $\mathrm{ZnO} / \mathrm{BR}$, que es interpenetrado por el electrolito en color púrpura, y el contraelectrodo en verde. 
Los datos experimentales se analizaron ajustando el modelo de circuito equivalente mostrado en la figura 9c. Los elementos de impedacia observados se interpretan de la siguiente manera: la resistencia en serie del conductor transparente $\left(R_{\mathrm{FTO}}\right)$ en la más alta frecuencia; la resistencia de tranferencia de carga del contraelectrodo al electrolito $\left(R_{C E}\right)$ aproximadamente a $100 \mathrm{kHz}$, que es imperceptible en este caso; y dos picos que se traslapan a frecuencias intermedias-bajas, que corresponden a la transferencia de carga en el fotoánodo. Los fenómenos distinguibles que ocurren en el fotoánodo son dos elementos en serie, el primero es la transferencia de carga del electrolito al $\mathrm{ZnO} / \mathrm{BR}$, que se comporta como una resistencia $\left(\mathrm{R}_{\mathrm{k}}\right)$ en paralelo a un capacitor no ideal $\left(\mathrm{CPE}_{\mathrm{k}}\right)$, con una tasa de transferencia $\mathrm{f}_{\mathrm{k}}$; el segundo elemento es la transferecia de carga del ZnO al FTO caracterizado por los elementos $R_{\mathrm{FTO/ZnO}}$ y CPE $\mathrm{FTO/ZnO}_{\text {[11] [12]. Para ajustar el }}$ modelo a los datos experimentales se utilizó la hoja de cálculo de Excel propuesta por [13]. En el cuadro 4 se comparan la eficiencia de trasferencia de carga del electrolito al ZnO/BR por medio de los valores de $R_{k}$ y $f_{k}$ extraídos del modelo para los fotoánodos fabricados por los tres métodos. El error del ajuste fue menor al $10 \%$.

Cuadro 4. Parámetros extraídos del análisis de impedancia electroquímica para la transferencia electrónica del electrolito a la superficie del ZnO/BR en las BRSSC

\begin{tabular}{|l|c|c|c|c|}
\hline & & SE & DC & PTES \\
\hline Resistencia de transferencia de carga & $\mathrm{R}_{\mathrm{k}}(\mathrm{k} \Omega)$ & 197 & 195 & 270 \\
\hline Tasa de transferencia de carga & $\mathrm{f}_{\mathrm{k}}(\mathrm{Hz})$ & 1.65 & 0.45 & 0.22 \\
\hline
\end{tabular}

Los valores de $R_{\text {FTO }}$ y $R_{C E}$, son inferiores a los $40 \Omega$ para todas las muestras indicando que no es el factor limitante de la celda. En contraste, para la $R_{k}$, las resistencias son del orden de los $200 \mathrm{k} \Omega$, similar a valores ya encontrado en otras referencias [14] [15]. La micrografía MEB de la figura 8 podría explicar la alta impedancia mostrada para las BRSSC. Estudios previos han demostrado que el número de capas de BR es una variable importante a optimizar para mejorar la trasferencia de carga a través del sistema. Se ha visto que múltiples capas de BR apiladas una sobre otra incrementa la fotocorriente hasta un número óptimo a partir del cual la respuesta empieza a bajar [15]. El exceso de BR sobre el ZnO podría resultar en aglomeración, lo cual inhibe al electrolito de alcanzar el ánodo, deteriorando así, la inyección de electrones. Para cada técnica se debe de optimizar el grosor de la capa de BR inmovilizada.

Los métodos de SE y DC resultan en celdas con $\mathrm{R}_{\mathrm{k}}$ comparables, ya que la interfaz es muy similar estructuralmente, pero se observa que $f_{k}$ es menor para SE. Esto demuestra que la orientación selectiva de la proteína que se obtiene en SE permite una tasa de generación de electrones más alta. Por su parte, la tcnica de funcionalización química tiene una $R_{k} 50 \%$ más alta, y una $f_{k}$ más baja. Aunque el ligando PTES facilita la inmovilización de la proteína en el sustrato, también aumenta la resistencia eléctrica del sistema, funcionando como capa dieléctrica. [10]. Podría ser conveniente usar el ligando $R$-triethoxysilane con un grupo funcional más pequeño en su terminal (por ejemplo, el aminofeniltrietoxisilano) y utilizar catalizadores de la reacción para controlar el crecimiento de la capa ligando. Además, el ligando debe de cumplir con el requisito fundamental de ser conductor.

\section{Respuesta fotoeléctrica del fotoánodo de BR/ZnO/FTO}

Para estudiar la respuesta fotoeléctrica de la capa de BR inmovilizada sobre el ZnO/FTO se se aplica la técnica cronopotenciométrica a la celda en condiciones de circuito abierto mientras el fotoánodo es sujeto a cambios de un estado oscuro a un estado iluminado y viceversa. En 
la figura 10 se muestran la fotorespuesta de los fotoánodos estudiados. El blanco utilizado (a), en este caso ZnO/FTO sin proteína, no presenta ninguna respuesta al cambio entre iluminado a oscuridad, demostrando que la luz UV está siendo efectivamente filtrada y que el ZnO no está generando respuesta fotoeléctrica. Al agregar la proteína al sistema se observa una diferencia de potencial entre los electrodos al cambiar de un estado de iluminación (ON) and un estado de oscuridad (OFF). Este fotovoltaje es producto de la diferencia en la densidad de carga entre el lado citoplasmático y el lado extracelular de la proteína BR formada cuando la molécula retinal bombea protones de un lado al otro de la MP.
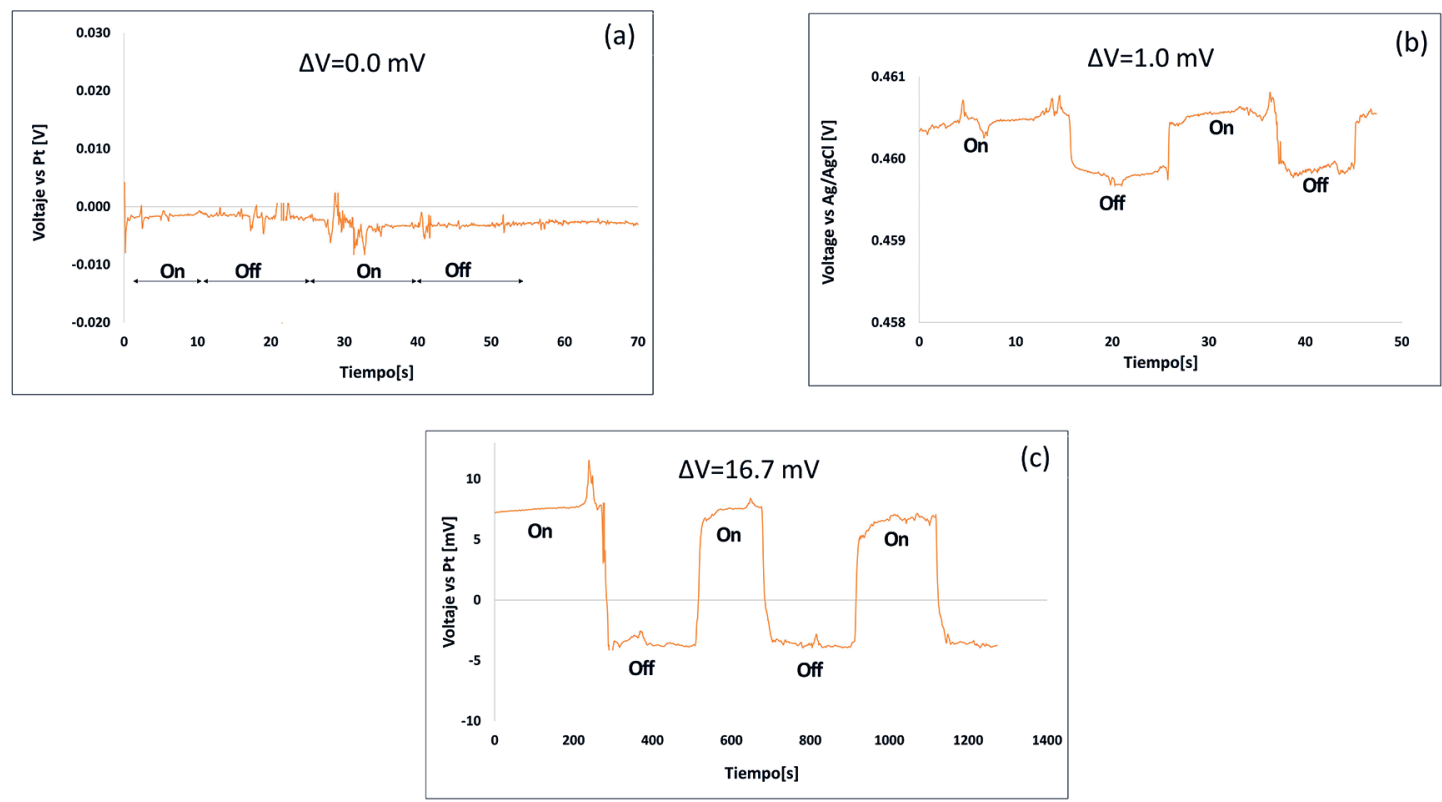

Figura 10. Foto-respuesta de los electrodos de a) ZnO/FTO (blanco) b) $\mathrm{BR} / \mathrm{ZnO} /$ FTO preparado por Dropcasting y c) BR/ZnO/FTO preparado por SE.

El campo eléctrico aplicado durante la inmovilización de BR por electroforésis tiene un importante efecto en la fotorespuesta del electrodo, el cual produce una diferencia de potencial 16 veces mayor a la que produce el electrodo preparado por DC. Estos resultados indican que el campo eléctrico resulta en orientación uniforme de las membranas sobre el sustrato de acuerdo al momento dipolar que existe entre el lado citoplasmático y el extracelular. Cada membrana de la multicapa genera un gradiente electroquímico tras completar el ciclo de la molécula retinal y bombear el protón de un lado al otro. Este gradiente electroquímico es un vector, con magnitud y dirección, que contribuye al total del potencial foto-electroquímico de la celda. Una orientación aleatoria como la que ocurre en el $D C$ resulta en vectores opuestos que se contrarrestan con lo que se da la pérdida de potencial. La orientación uniforme resulta en maximización de la suma de vectores y permite obtener fotovoltajes mucho más altos, tal como lo comprueban nuestros resultados. 


\section{Conclusiones y recomendaciones}

La proteína BR fue inmovilizada en ZnO nanoestructurado utilizando tres técnicas diferentes y la viabilidad y eficiencia de los fotoánodos preparados para su uso en celdas bio-fotovoltaicas fueron investigados. Los resultados de AFM confirman que la morfología de la capa de ZnO es bastante rugosa y con poros altamente desordenados, lo que mejora la absorción de la proteína. Para las tres técnicas se logró optimizar el proceso de inmovilización y de secado. La funcionalidad de la proteína inmovilizada se confirmó mediante espectroscopia UV-vis al observarse los picos de absorción característicos de la conformación de la molécula retinal que inicia el bombeo de protones. La impedancia electroquímica de los foto-ánodos revela que la técnica de SE resulta en la tasa de trasnferencia de foto-electrones más veloz, seguida por la DC, mientras la técnica de PTES resulta en una resistancia eléctrica siginificativamente mayor y una tasa de transferencia más lenta. La actividad de la BR también se comprobó cuando en presencia de irradiación de luz visible se midieron foto-voltajes de 1 y $16 \mathrm{mV}$ para los fotoánodos preparados mediante las técnicas de DC y SE respectivamente. Estos resultados indican que la orientación de la proteína con el lado citoplasmático de la BR en contacto con el $\mathrm{ZnO}$ promueve un flujo unidireccional de electrones mientras que si el acomodo es aleatorio se contrarrestan cargas transferidas que disminuyen la eficiencia del sistema. Por otro lado, mediante la técnica de funcionalización con molécula PTES no se lograron registrar fotovolatajes debido al agregado de resistencia en serie que agrega la capa ligando al sistema; no obstante, se comprobó el cambio de energía superficial del ZnO al requerirse menores tiempos de incubación para realizar la inmovilización.

En comparación con tintes sintéticos, las celdas aquí reportadas generan un foto-voltaje relativamente bajo que se atribuyen a los altos valores de Rk medidos. El tipo de enlace y la interfaz que se forme entre la proteína y el ZnO es determinante para mejorar el desempeño de las celdas BRSSC. Las causas a la gran impedancia deben de seguir siendo estudiadas para llegar a utilizarse para esta aplicación. La caracterización precisa de las propiedades fotoeléctricas de las láminas de BR es esencial para el diseño y el desarrollo dispositivos sensitivos basado en este biomaterial. Debido a la gran cantidad de variables involucradas en el proceso, se están trabajando sobre modelos matemáticos para ilustrar la interacción entre las variables y la naturaleza de la BR (Wei. Wei et al., 2005). Más aún, los foto-voltajes medidos para las muestras inmovilizadas mediante las técnicas DC y SE podrían encontrar aplicación en dispositivos sensores de luz y de imagen tales como transductores de señal optoeléctrica ultrarrápida, fotodetectores y transistores MOSFET monolíticamente integrados (Shin, Bhattacharya, Xu, \& Varo, 2005; Wei. Wei et al., 2005). 


\section{Referencias}

[1] N. Asim et al., «A review on the role of materials science in solar cells», Renew. Sustain. Energy Rev., vol. 16, n.o 8, pp. 5834-5847, 2012.

[2] K. Tanabe, «Low-cost high-efficiency solar cells with wafer bonding and plasmonic technologies», PhD Thesis, California Institute of Technology, 2008.

[3] B. O'regan y M. Grätzel, «A low-cost, high-efficiency solar cell based on dye-sensitized colloidal TiO 2 films», nature, vol. 353, n.o 6346, pp. 737-740, 1991.

[4] R. Simón Vázquez, Influencia de la movilidad de las hélices en la función de la bacteriorodopsina. Universitat Autònoma de Barcelona, 2009.

[5] S. Y. Lee, H. N. Chang, Y. S. Um, y S. H. Hong, «Bacteriorhodopsin production by cell recycle culture of Halobacterium halobium», Biotechnol. Lett., vol. 20, n.o 8, pp. 763-765, 1998.

[6] L. J. Miercke, P. E. Ross, R. M. Stroud, y E. A. Dratz, «Purification of bacteriorhodopsin and characterization of mature and partially processed forms.», J. Biol. Chem., vol. 264, n.o 13, pp. 7531-7535, 1989.

[7] Y. Köseoßlu, «PEG-assisted hydrothermal synthesis and characterization of Co0. 1ZnO. 90 DMS nanoparticles», J. Magn. Magn. Mater., vol. 373, pp. 195-199, 2015.

[8] T. K. Pathak, V. Kumar, H. C. Swart, y L. P. Purohit, «Electrical and optical properties of p-type codoped ZnO thin films prepared by spin coating technique», Phys. E Low-Dimens. Syst. Nanostructures, vol. 77, pp. 1-6, 2016.

[9] V. Thavasi et al., «Study on the feasibility of bacteriorhodopsin as bio-photosensitizer in excitonic solar cell: a first report», J. Nanosci. Nanotechnol., vol. 9, n.o 3, pp. 1679-1687, 2009.

[10] C. G. Allen et al., «Surface modification of $\mathrm{ZnO}$ using triethoxysilane-based molecules», Langmuir, vol. 24, n.o 23, pp. 13393-13398, 2008.

[11] R. Kern, R. Sastrawan, J. Ferber, R. Stangl, y J. Luther, «Modeling and interpretation of electrical impedance spectra of dye solar cells operated under open-circuit conditions», Electrochimica Acta, vol. 47, n.o 26, pp. 4213-4225, 2002.

[12] Q. Wang, J.-E. Moser, y M. Grätzel, «Electrochemical impedance spectroscopic analysis of dye-sensitized solar cells», J. Phys. Chem. B, vol. 109, n.o 31, pp. 14945-14953, 2005.

[13] S. Sarker, A. J. Ahammad, H. W. Seo, y D. M. Kim, «Electrochemical impedance spectra of dye-sensitized solar cells: fundamentals and spreadsheet calculation», Int. J. Photoenergy, vol. 2014, 2014.

[14] J. Shin, P. Bhattacharya, J. Xu, y G. Váró, «Monolithically integrated bacteriorhodopsin-GaAs/GaAlAs phototransceiver:? erratum», Opt. Lett., vol. 30, n.o 3, pp. 335-335, 2005.

[15] W. W. Wang, G. K. Knopf, y A. S. Bassi, «Photoelectric properties of a detector based on dried bacteriorhodopsin film», Biosens. Bioelectron., vol. 21, n.o 7, pp. 1309-1319, 2006. 